\title{
Traffic-land use compatibility and street design impacts of automated driving in Vienna, Austria
}

\author{
Emilia M. Bruck \\ future.lab Research Centre and Research \\ Unit for Local Planning, TU Wien, \\ emilia.bruck@tuwien.ac.at
}

\author{
Aggelos Soteropoulos \\ future.lab Research Centre and Research \\ Unit for Transportation System Planning, TU \\ Wien \\ aggelos.soteropoulos@tuwien.ac.at
}

\begin{abstract}
The potential rise of automated vehicles (AVs) may significantly impact future traffic volumes, in turn affecting urban street designs and adjacent land use. While integrated studies on potential traffic and land-use changes due to AVs largely concern issues of location choice and changing settlement patterns, assessments of how $A V s$ may influence the quality of streets depending on the requirements of adjacent land use remain scarce. This paper presents an integrated assessment of the urban effect of AVs on traffic and neighborhoods in Vienna. It provides a methodology to assess whether changing traffic volumes are compatible with the land use of a given neighborhood to approximate street space requirements for shared automated shuttles and to visualize possible trajectories of spatial transformation by considering local development goals. The results show that the opportunities to convert street space and the risks of environmental harm due to AVs will vary across neighborhoods and street typologies. It is crucial for policymakers and planners to consider such contextual differences to gain better insight into the functional requirements and urban consequences of AVs. This assessment aims to shed light on the possible trade-offs of a system change in favor of AVs to help evaluate adequate operational conditions and inform proactive traffic and urban design policies to harness possible implications.
\end{abstract}

Keywords: Automated driving, traffic-land use compatibility analysis, street design studies

\section{Introduction}

The introduction of automated driving to urban environments may significantly alter mobility patterns and transport demand, which will, in turn, affect the intensity of street life, infrastructural requirements, and urban form. How future changes may spatially manifest will differ depending on existing urban structures, land use, and street typologies. This gives reason to assume that the spatial impact of automated vehicles (AVs) will occur unevenly across cities, affecting some neighborhoods more than others. However, despite the surging interest in spatial implications of AVs in recent years, there is a lack of studies that look at effects on urban form in an integrated manner (Stead \& Vaddadi, 2019). Although models exist that examine the correlation between traffic changes induced by different types

Copyright 2022 Emilia M. Bruck \& Aggelos Soteropoulos

http://dx.doi.org/10.5198/jtlu.2022.2089

ISSN: 1938-7849 | Licensed under the Creative Commons Attribution - Noncommercial License 4.0

The Journal of Transport and Land Use is the official journal of the World Society for Transport and Land Use (WSTLUR) and is published and sponsored by the University of Minnesota Center for Transportation Studies.

\section{Article history:}

Received in revised form:

October 27, 2021

Available online: February 21, 2022 
of AVs and land use, they largely address impacts on parking, location choice, and changing settlement patterns, i.e., urban sprawl or re-urbanization (Gelauff et al., 2017; Wellik \& Kockelman, 2020; Zhang $\&$ Wang, 2020). Integrated assessments at the neighborhood scale, however, remain scarce.

In recent years, numerous studies were conducted to investigate first-order effects ${ }^{1}$ of automated driving and to elicit potential changes in vehicle miles travelled, ease of travel, and mode choice depending on scenario-based assumptions (e.g., Boesch et al., 2016; Liu et al., 2017; Zhang et al., 2018). The studies which examine impacts on urban form (secondary effects according to Milakis et al., 2017) using simulations address issues of urban sprawl, changing parking needs, and provision of infrastructure (e.g., Thakur et al., 2016; Zhang et al., 2015). With regards to parking, it was shown that high levels of shared automated vehicles (SAVs) may considerably reduce urban parking demands, while the primacy of single occupied vehicles could exasperate the need for parking (Soteropoulos et al., 2019). Recognizing that an uptake of automated driving will unfold gradually and along various transitional pathways (Fulton et. al, 2017), more recent studies point towards a growing demand for pickup and drop-off infrastructure and a trade-off between an increase in traffic, e.g., due to deadheading (zero-passenger vehicle travel) and savings in parking space (Kondor et al., 2020). Such studies show that changes in parking demand and land use are likely to be unevenly distributed across cities' districts, from the urban core to suburban areas (Kondor et al., 2020; Zhang \& Wang, 2020).

Adding to studies that differentiate traffic and spatial implications of AVs according to land use and urban form, this paper presents a study on urban traffic compatibility and street design impacts conducted for the city of Vienna, Austria. The aim of this paper is to provide an integrated assessment of AVs' traffic and urban effects at the neighborhood level and to emphasize its informative value for the debate on operating conditions and geographic scope, as well as policy regulations for automated driving (Stayton \& Stilgoe, 2020). We argue that integrated assessments and context-specific design strategies have a threefold benefit.

First, it shows to what extent changing traffic volumes and mobility patterns are compatible with different neighborhoods depending on their urban form, land use, and corresponding demands for curb access and use of public space. Second, knowledge is gained regarding the effects on street life and infrastructural requirements, which automated driving may strain or alleviate in some street typologies more than in others. Third, design strategies for reallocating urban space are explored that add to the livability of streets while integrating measures to optimize shared automated mobility systems, such as designated pickup and drop-off points.

The paper is structured in four parts. The first part introduces the research approach and the methodologies developed to examine urban impacts in different neighborhoods and street typologies with regards to: a.) compatibility changes between traffic demand and land use; b.) curb access demands; and c.) possible design strategies that integrate generated results with literature findings and urban development goals set by the City of Vienna.

Part two presents the results of the spatial assessments and design strategy for one of the three study areas in Vienna. In the third part, the findings are discussed comparatively, juxtaposing the impacts of modified traffic demand, mobility patterns, and spatial demands across urban neighborhoods. Additionally, insights concerning policy considerations are deduced, methodological limitations are highlighted, and directions for further research are elaborated.

In the final part, the conclusions of the study are summarized.

\footnotetext{
${ }^{1}$ According to Milakis et al. (2017) societal and policy relevant implications of introducing AVs may be categorized as: a.) first-order effects (traffic, travel cost, and travel choices); b.) second-order effects (vehicle ownership and sharing, location choices and land use, and transport infrastructure); and c.) third-order effects (energy consumption, air pollution, safety, social equity, economy, and public health).
} 


\section{$2 \quad$ Method}

\subsection{Base-line simulation of scenarios with AVs}

The in-depth study of second order effects presented in this paper was conducted as part of a larger research project analyzing traffic, energy, and spatial impacts of automated vehicles in the greater Vienna region. It therefore builds on the output data from scenarios with AVs, previously developed and modelled in MATSim. To distinguish which data was retrieved from the scenario-based model and which data sets were additionally calculated as input variables for the study at hand, the three scenarios (2.1.1.), the simulation approach (2.1.2), and the use of its output (2.1.3.) are briefly described.

\subsubsection{Three scenarios with AVs}

Based on an extensive literature review of earlier studies that address AVs' impact on travel behavior, three scenarios were developed that differ in their underlying assumptions (Table 1): The first scenario assumes the introduction of shared automated shuttles (with 10 seats) providing on-demand door-todoor travel. The second scenario assumes that shared automated shuttles run on-demand, but stop at designated collection points, i.e., existing bus stops. The third scenario assumes the automation of the current number of private vehicles, i.e., private AVs, with a utility increase of $25 \%$ due to higher levels of comfort and the possibility to engage in non-driving related tasks. The utility increase reflects earlier studies that assume the reduced value of time, varying between $-20 \%$ and $-50 \%$ (e.g., Auld et al., 2018; Boesch et al., 2018), and corresponds with the results of stated preference surveys on the topic (see Harb et al., 2021, for an overview).

Since high penetration rates of private $\mathrm{AVs}$ could potentially allow for shorter distances between vehicles, an overall capacity increase of $40 \%$ was additionally assumed. Earlier studies have assumed a capacity increase between 10\% and 80\% (Childress et al., 2015; Friedrich, 2016; Meyer et al., 2017).

Table 1. Overview of the three scenarios with AVs implemented and modelled in MATSim

\begin{tabular}{|c|c|c|}
\hline $\begin{array}{c}\text { Scenario 1 } \\
\text { Automated shuttles door-to-door service }\end{array}$ & $\begin{array}{c}\text { Scenario 2 } \\
\text { Automated shuttles stop-based service }\end{array}$ & $\begin{array}{c}\text { Scenario 3 } \\
\text { Private AVs }\end{array}$ \\
\hline $\begin{array}{c}\text { Automated shuttles as an additional trans- } \\
\text { port option with door-to-door service }\end{array}$ & $\begin{array}{c}\text { Automated shuttles as an additional } \\
\text { transport option with stop-based service } \\
\text { (existing bus stops) }\end{array}$ & $\begin{array}{c}\text { Automation of current private } \\
\text { vehicles with an increase of } \\
\text { utility of } 25 \% \text { and an overall } \\
\text { capacity increase of } 40 \%\end{array}$ \\
\hline
\end{tabular}

\subsubsection{The simulation approach}

The agent-based transport simulation package was used to model daily activity plans in a realistic transportation network, in this case comprising the city of Vienna and the neighboring municipalities Mödling and Baden, and to observe how agents, i.e., travelers and vehicles, navigate the network at the individual level. In contrast to earlier studies on changes in travel behavior with AVs (e.g., Spieser et al., 2014), which did not consider congestion and explicit traffic assignments, MATSim included these issues. Using MATSim, it is possible to optimize travel plans of a synthetic population under specific travel constrains and to investigate the impacting variables of mode choice (Liu et al., 2017). In MATSim, all agents try to maximize their utility in a co-evolutionary process until a dynamic user equilibrium is reached, meaning that no agent can further improve their mobility behavior alone by modifying their plan (Horni et al., 2016; Liu et al., 2017). 
Mobile phone data from the Austrian mobile phone provider A1, i.e., anonymized motion trajectories of mobile phones connecting to radio cells, was used as input data on agents' starting points, end points, and activity times for the simulation. Based on an automated process detecting anonymized movement trajectories in mobile phone data, a randomized data sample was generated and spatially distributed over the entire analysis area, forming the basis for the simulation's synthetic population. The synthetic population (agents) comprised the population of the analysis area, i.e., the city of Vienna and the neighboring municipalities Mödling and Baden. Due to computing power issues and calculation times, the simulation was based on $15 \%$ of the synthetic population and was then extrapolated.

To analyze travel behavior changes for a typical weekday, the simulation used mobile phone data from Wednesday, October 2018. Public transport was integrated using existing timetables, whereas distances travelled by pedestrians and cyclists were approximated by means of Euclidean distance and a detour factor to reduce calculation time.

\subsubsection{Use of simulation results}

The MATSim simulation model provided the following output data sets on a city scale:

(1) Modal split changes excl. pedestrian traffic (city and district scale);

(2) Number of trips performed by automated shuttles;

(3) Percentage of rejected trips by automated shuttles;

(4) Number of empty trips by automated shuttles;

(5) Occupancy rates of automated shuttles;

(6) Average waiting times by passengers;

(7) Average travel time with automated shuttles;

(8) Average travel distance with automated shuttles.

Issues of land use or urban form were not considered as part of the MATSim simulation and were, therefore, not part of its output. To analyze urban implications at a street level, it was necessary to specify relevant, although missing, traffic variables in order to study traffic land use compatibility and street design changes. In effect, the following parameters were additionally calculated for selected street segments:

(1) Change in traffic volume (number of vehicles at peak hour);

(2) Number of passenger pickup and drop-off by automated shuttles throughout the day;

(3) Number of waiting automated shuttles throughout the day.

Calculating these variables for all scenarios described above made it possible to select urban locations and scenario conditions which show the most distinct effects, but are representative for the neighborhoods (2.2.1). Moreover, it was possible to delineate the following variables of functional demand and approximate activity levels for the street segments selected:

- Density of passenger pickup and drop-off events along a street space;

- Demand for passenger loading zones to facilitate peak hour pickup and drop-off;

- Spatial demand of waiting vehicles.

The quantitative approximation of spatial impacts provided the basis for a more detailed conception of street design transformations which were substantiated by literature-based and normative assumptions. 


\subsection{Integrated assessment of impacts on urban street designs}

\subsubsection{Site selection based on land-use types and street typologies}

The site selection for analyzing impacts on urban street designs is based on the simulation results. Scenario impacts regarding vehicle kilometers travelled and loading/unloading events by AV shuttles are compared on a city scale and areas with high activity levels are determined. Aiming to assess impacts in different urban environments, the sites are selected based on the heterogeneity of adjacent land-use types and street typologies. The following three street segments were selected: 1) an inner-city commercial street; 2) a suburban arterial with a tramway; and 3) an industrial access street (Figure 1).

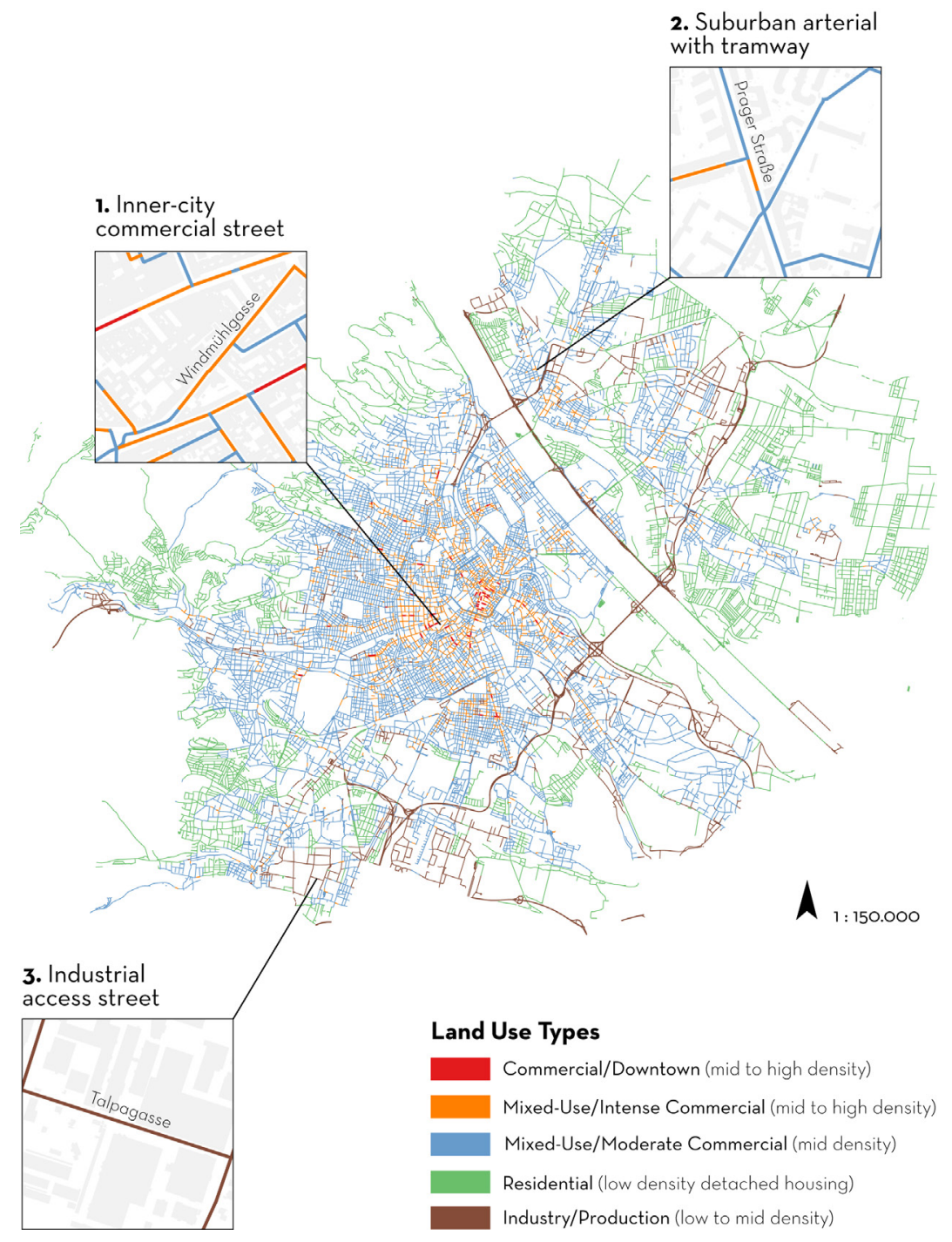

Figure 1. Overview of the selected sites for analysis 


\subsubsection{Compatibility assessment of automated driving}

The compatibility assessment of automated driving in street spaces is based on the "compensatory approach" ${ }^{2}$ most recently applied by Bühlmann and Laube (2013: 33). The following section describes the steps carried out as part of the compensatory approach and that were conducted using ArcGIS (see also Soteropoulos et al., 2021):

\section{a) Determining the maximum compatible traffic volume based on area categories}

To determine the maximum compatible traffic volume for individual street segments, the area type, building volume and age, and adjacent land uses were considered. After integrating data on a) area types and building age, b) zoning categories, and c) the number of shops and businesses, five different area categories were distinguished:

- Commercial center/ downtown: predominantly urban perimeter blocks with more than four stories, and a high degree of business and retail;

- Mixed-use area with intense commercial use: predominantly urban perimeter blocks with more than four stories, and a moderate to a high degree of business and retail;

- Mixed-use area with moderate commercial use: predominantly urban perimeter blocks with more than four stories or semi-open developments with two to four stories, and a moderate degree of business and retail;

- Low-density residential area: predominantly detached or semi-detached buildings and allotments with occasional shops or other functions with a high public frequency;

- Industrial area: predominantly industrial use with low residential use and no functions with high public frequency, such as housing or retail.

Maximum compatible traffic volumes, i.e., the number of motorized vehicles at peak hour, were assigned to the defined area types based on the following assumptions (Table 2): In the city center, i.e., areas with a high density of buildings, retail, and business, the requirements for street design elements and urban quality are highest. There is a high demand by pedestrians and cyclists (e.g., residents, employees, customers, etc.) to move, stroll, linger, and cross street spaces. In comparison, in residential neighborhoods with predominantly detached or semi-detached buildings or industrial areas, where the density of buildings, retail, and business is lower or not even present, requirements for street design elements are lower (Bühlmann \& Laube, 2013; Gehl Architects, 2009; von Mörner et al., 1984).

\footnotetext{
2 The so-called compensatory approach by von Mörner et al. (1984), redefined by Bühlmann and Laube (2013), makes it possible to assess the compatibility of motorised traffic with the needs of other forms of use and users, i.e., pedestrians and cyclists. In contrast to other existing qualitative and broad approaches (e.g., Baier et al., 2011; Frehn, 2013), this approach quantifies the specific characteristics of a street space, e.g., typology, land-use types etc., in order to assess the level of compatibility between car traffic and other demands in a more detailed manner.
} 
Table 2. Overview of area categories and traffic-land use compatibility

\begin{tabular}{|c|c|}
\hline Area Category & $\begin{array}{l}\text { Traffic-Land Use Compatibility (number of vehicles at } \\
\text { peak hour) }\end{array}$ \\
\hline \multirow[t]{5}{*}{ Commercial / Downtown } & $<=20$ (well compatible) \\
\hline & $>20-50$ (compatible) \\
\hline & $>50-150$ (only just compatible) \\
\hline & $>150-400$ (not compatible) \\
\hline & >400 (completely not compatible) \\
\hline \multirow[t]{5}{*}{ Mixed-use area with intense commercial use: } & $<=50$ (well compatible) \\
\hline & $>50-150$ (compatible) \\
\hline & $>150-400$ (only just compatible) \\
\hline & $>400-600$ (not compatible) \\
\hline & $>600$ (completely not compatible) \\
\hline \multirow[t]{5}{*}{ Mixed-use area with moderate commercial use } & $<=150$ (well compatible) \\
\hline & $>150-\mathbf{4 0 0}$ (compatible) \\
\hline & $>400-600$ (only just compatible) \\
\hline & $>600-1000$ (not compatible) \\
\hline & >1000 (completely not compatible) \\
\hline \multirow[t]{5}{*}{ Low density residential area } & $<=400$ (well compatible) \\
\hline & $>400-\mathbf{6 0 0}$ (compatible) \\
\hline & $>600-1000$ (only just compatible) \\
\hline & $>1000-1200$ (not compatible) \\
\hline & $>1200$ (completely not compatible) \\
\hline \multirow[t]{5}{*}{ Industrial area } & $<=600$ (well compatible) \\
\hline & $>600-1000$ (compatible) \\
\hline & >1000 - 1200 (only just compatible) \\
\hline & $>1200-1500$ (not compatible) \\
\hline & >1500 (completely not compatible) \\
\hline
\end{tabular}

\section{b) Adapting the maximum compatible traffic volume based on street characteristics}

The area categories distinguished in the first step, represent an initial classification. But since street designs, traffic volumes, and modal mix may significantly vary within the same area category, levels of maximum compatible traffic volume need to be fine-tuned according to a street segment's characteristics. To adapt the levels of maximum compatible traffic volume, the following criteria are considered:

a) Distribution of space;

b) Use by pedestrians and cyclists;

c) Speed;

d) Heavy goods vehicle traffic;

e) Green and design elements;

f) Crossability. 
The assessment of street characteristics builds on data sets from the city of Vienna (e.g., distribution of space) and the simulation results (e.g., speed). Following the logic of a compensatory approach, the defined criteria serve as compensatory elements. Depending on their availability, levels of maximum compatible traffic volume are adapted by an increase or decrease of +100 to -100 vehicles at peak hours. In effect, high crossability values, which indicate the number of available crosswalks, may positively affect the compatibility of traffic volumes, while the opposite is the case for low crossability values. The assessment of street characteristics and adaptation of max. compatible traffic volumes take the functional demand of adjacent land uses and other mobility users (e.g., pedestrians and cyclists) into account. Tables 3 to 5 give an overview of how the different criteria are assessed.

Table 3. Overview of the criteria "distribution of space," "use by pedestrians and cyclists," "speed," and "heavy goods vehicle traffic" and adaptation values

\begin{tabular}{|c|c|c|c|c|c|}
\hline $\begin{array}{l}\text { a) Distribution of } \\
\text { space } \\
\text { Ratio between } \\
\text { street space for } \\
\text { pedestrians and } \\
\text { cyclists to street } \\
\text { space for motor } \\
\text { vehicle traffic }\end{array}$ & $\begin{array}{l}\text { b) Use by pedes- } \\
\text { trians and cyclists }\end{array}$ & $\begin{array}{l}\text { c) Speed } \\
\text { Average speed on } \\
\text { the street segment }\end{array}$ & $\begin{array}{l}\text { d) Heavy goods } \\
\text { vehicle traffic } \\
\text { HGV share of the } \\
\text { total motor vehicle } \\
\text { traffic volume }\end{array}$ & $\begin{array}{l}\text { Levels of compat- } \\
\text { ibility with needs } \\
\text { of adjacent land } \\
\text { use and users }\end{array}$ & $\begin{array}{l}\text { Adaptation of the } \\
\text { max. compatible } \\
\text { traffic volume }\end{array}$ \\
\hline$>=1.25$ & very low & $<=10 \mathrm{~km} / \mathrm{h}$ & $\begin{array}{c}\text { very low } \\
\text { (residential streets, } \\
\text { pedestrian- and } \\
\text { encounter zones) }\end{array}$ & ++ well compatible & $\begin{array}{c}+100 \text { vehicles/ } \\
\text { peak hour }\end{array}$ \\
\hline 1.00 to $<1.25$ & low & $\begin{array}{c}>10 \mathrm{~km} / \mathrm{h}<=20 \\
\mathrm{~km} / \mathrm{h}\end{array}$ & $\begin{array}{c}\text { low } \\
\text { (tertiary roads, ac- } \\
\text { cess roads etc.) }\end{array}$ & + compatible & $\begin{array}{c}+50 \text { vehicles/peak } \\
\text { hour }\end{array}$ \\
\hline 0.75 to $<1.00$ & medium & $\begin{array}{c}>20 \mathrm{~km} / \mathrm{h}<=30 \\
\mathrm{~km} / \mathrm{h}\end{array}$ & $\begin{array}{c}\text { medium } \\
\text { (secondary roads) }\end{array}$ & $\begin{array}{l}\text { o only just com- } \\
\text { patible }\end{array}$ & $\begin{array}{c} \pm 0 \text { vehicle/peak } \\
\text { hour }\end{array}$ \\
\hline 0.5 to $<0.75$ & high & $\begin{array}{c}>30 \mathrm{~km} / \mathrm{h}<=40 \\
\mathrm{~km} / \mathrm{h}\end{array}$ & $\begin{array}{c}\text { high } \\
\text { (primary roads, } \\
\text { Federal roads) }\end{array}$ & - not compatible & $\begin{array}{c}-50 \text { vehicles/peak } \\
\text { hour }\end{array}$ \\
\hline$<0.5$ & very high & $>40 \mathrm{~km} / \mathrm{h}$ & $\begin{array}{l}\text { very high } \\
\text { (Motorways and } \\
\text { expressways as } \\
\text { well as streets in } \\
\text { industrial areas) }\end{array}$ & $\begin{array}{l}\text {-- Completely not } \\
\text { compatible }\end{array}$ & $\begin{array}{c}\text { - } 100 \text { vehicles/peak } \\
\text { hour }\end{array}$ \\
\hline
\end{tabular}

Table 4. Overview of the criterion "green and design elements" and adaptation values

\begin{tabular}{cccccc}
\hline & \multicolumn{5}{c}{ Number of Trees and Bushes per 100 meters } \\
\hline $\begin{array}{c}\text { Number of design elements per } \\
\mathbf{1 0 0} \text { meters }\end{array}$ & 0 & 1 to 4 & 5 to 9 & 10 to 14 & 15 or more \\
\hline 0 & - & - & - & 0 & 0 \\
1 & - & 0 & 0 & + & + \\
2 to 4 & 0 & + & + & ++ & ++ \\
5 or more & + & ++ & ++ & ++ \\
\hline
\end{tabular}

-- very low: completely not compatible (-100 vehicle/peak hour); - low: not compatible ( -50 vehicle/peak hour);

o medium: only just compatible ( \pm 0 vehicle/peak hour); + high: compatible ( +50 vehicle/peak hour);

++ very high: well compatible (+100 vehicle/peak hour) 
Table 5. Overview of the criterion "crossability" and adaptation values

\begin{tabular}{|c|c|c|c|c|c|c|c|c|c|c|c|c|c|c|c|c|c|c|}
\hline \multirow[b]{2}{*}{$\begin{array}{c}\text { Area } \\
\text { Category }\end{array}$} & \multicolumn{18}{|c|}{ Crossability - Number of pedestrian crosswalks per 100 meters } \\
\hline & 0 & 0,1 & 0,2 & 0,3 & 0,4 & 0,5 & 0,6 & 0,7 & 0,8 & 0,9 & 1,0 & 1,1 & 1,2 & 1,3 & 1,4 & 1,5 & 1,6 & $1,7+$ \\
\hline $\begin{array}{l}\text { Commercial } \\
\text { / Downtown }\end{array}$ & -- & - & - & - & - & - & - & - & - & - & - & o & o & o & + & + & + & ++ \\
\hline $\begin{array}{l}\text { Mixed-use } \\
\text { area with } \\
\text { intense com- } \\
\text { mercial use }\end{array}$ & - & - & - & - & - & - & - & - & - & o & o & o & + & + & + & ++ & ++ & ++ \\
\hline $\begin{array}{l}\text { Mixed-use } \\
\text { area with } \\
\text { moderate } \\
\text { commercial } \\
\text { use }\end{array}$ & -- & -- & -- & -- & - & - & - & o & o & o & + & + & + & ++ & ++ & ++ & ++ & ++ \\
\hline $\begin{array}{l}\text { Low-density } \\
\text { residential } \\
\text { area }\end{array}$ & -- & -- & - & - & - & o & o & o & + & + & + & ++ & ++ & ++ & ++ & ++ & ++ & ++ \\
\hline $\begin{array}{c}\text { Industrial } \\
\text { area }\end{array}$ & -- & - & - & o & o & o & + & + & + & ++ & ++ & ++ & ++ & ++ & ++ & ++ & ++ & ++ \\
\hline
\end{tabular}

-- very low: completely not compatible (-100 vehicle/peak hour); - low: not compatible (-50 vehicle/peak hour); o medium: only just compatible ( \pm 0 vehicle/peak hour); + high: compatible ( +50 vehicle/peak hour);

++ very high: well compatible (+100 vehicle/peak hour)

\section{c) Comparing the actual traffic volume with the adapted maximum compatible traffic volume}

Once the level of maximum compatible traffic volumes is adapted according to street characteristics, the final value is compared to the actual traffic volumes in selected street segments. For this study, the comparison is conducted for each of the modelled scenarios, i.e., the reference scenario and the three scenarios with $\mathrm{AVs}$, in order to compare the compatibility of scenario-based traffic volumes with the demands of adjacent land uses. The assessment is conducted for the entire street network of Vienna. Table 6 illustrates how to conduct the comparison by taking the example of a street segment in a mixed-use neighborhood with intense commercial activity in Vienna, Austria. 
Table 6. Compatibility assessment for an exemplary street segment: Current levels of traffic are compared to the adapted maximum compatible traffic volume, which is changed according to the evaluation of criteria in a given street segment

\begin{tabular}{|c|c|c|c|c|c|c|c|c|c|c|c|}
\hline \multicolumn{12}{|c|}{ Adaptation of max. compatible traffic volume } \\
\hline & $\begin{array}{c}\text { Max. } \\
\text { compatible } \\
\text { traffic } \\
\text { volume for } \\
\text { area category }\end{array}$ & $\mathrm{C} 1$ & $\mathrm{C} 2$ & $\mathrm{C} 3$ & $\mathrm{C} 4$ & C5 & C6 & Sum & $\begin{array}{l}\text { Adapted } \\
\text { max. } \\
\text { compat- } \\
\text { ible traffic } \\
\text { volume }\end{array}$ & $\begin{array}{c}\text { Current } \\
\text { traffic } \\
\text { volume }\end{array}$ & $\begin{array}{l}\text { Assessment of } \\
\text { compatibility }\end{array}$ \\
\hline $\begin{array}{c}\text { Street } \\
\text { segment } \\
\text { in mixed- } \\
\text { use area } \\
\text { with } \\
\text { intense } \\
\text { com- } \\
\text { merce }\end{array}$ & 150 & +175 & -25 & -100 & +50 & -25 & -50 & +25 & $\begin{array}{c}<=75(++) \\
>75 \text { bis } 175 \\
(+) \\
>175 \text { bis } \\
425(0) \\
>425 \text { bis } \\
625(-) \\
>625(--)\end{array}$ & 157 & + compatible \\
\hline
\end{tabular}

$\mathrm{C} 1$ = criterion "distribution of space"; $\mathrm{C} 2$ =criterion "green and design elements";

C3 = criterion "use by pedestrians and cyclists"; C4 = criterion "crossability"; C5 = criterion "speed";

C6 = criterion "heavy goods vehicle traffic"

\subsubsection{Approximating spatial demands of shared automated shuttles}

\section{a) Density of passenger pickups and drop-offs}

With the rise of AVs, an increasing amount of street space will be needed for picking up and dropping off passengers (Stead \& Vaddadi, 2019). To approximate the intensity of pickup and drop-off events for this study, we first evaluate the hourly distribution of loading/unloading moments taking place within a given street segment over the course of the day. Depending on land use and street typology, this reveals identifiable peak hours for some streets and a more or less even distribution throughout the day for others. In a second step, the density of pickup and drop-off events is approximated. The peak hour data is spatially evaluated in relation to existing urban functions (trip sources and destinations) along a street. The results are less conclusive than real-time data since traffic generation rates are not differentiated according to land-use types (e.g., residential use, commercial use, etc.). Nonetheless, the assessment highlights destinations with higher land-use intensity (e.g., population and workplace density, number of customers and guests, etc.) and points towards areas that may be affected by changing spatial demands (Oblozinska \& Axhausen, 2004).

\section{b) Passenger loading zones}

To approximate loading zone requirements for the street segments in this study, the calculation is based on earlier studies that examined the effectiveness and dimensioning of dedicated collection points for shared on-demand ride services. For instance, in a study conducted as part of Seattle's Mobility Playbook (Schwartz, 2017), loading zone requirements were calculated for different land-use types (e.g., residential, commercial, office, public facility) based on corresponding peak-hour trip generation rates. The underlying assumption was that within a given hour up to 80 loading or unloading moments $(1 \mathrm{~h} / 45 \mathrm{~s}=80)$ could successively take place at a single loading zone. In contrast, a study by the International Transport Forum assumed an average loading zone size of 15 meters, placed at a distance of 150 to 200 meters (ITF, 2018: 66). Larger loading zones were assigned to destinations of high demand, e.g., schools or shopping centers. Finally, in studies conducted for San Francisco (Fehr \& Peers, 2018) and Cincinnati 
(Fehr \& Peers, 2019) loading zone dimensions were differentiated depending on their location along an urban block.

For the street segments selected, loading zone requirements are determined based on the number of peak-hour pickup and drop-off events, and adapted depending on the location of a loading zone, e.g., near an intersection or in the middle of an urban block. In the event that an AV shuttle would approach an occupied loading zone and need to drive to the nearest free zone, additional loading zones are located at a distance of 150 to 200 meters.

\section{c) Parking demand for waiting vehicles}

Finally, to approximate the short-term parking need for empty vehicles in this study, the maximum number of simultaneously waiting AV shuttles is derived from the median waiting time of AV shuttles in a given street segment. Due to modelling a $15 \%$ sample, results are influenced by the multiplication factor. Thus, absolute values need to be treated with care.

\subsubsection{Additional criteria for changes in urban street design}

The approximated spatial impacts of AVs are supplemented by literature-based and normative assumptions to substantiate the direction of spatial transformation. This is because any opportunities to reallocate urban space will ultimately depend on public policy and regulation. With AVs being only one of many mobility options on the rise, future street designs will be shaped by how the growing diversity of uses and spatial needs are publicly governed (Figure 2). In three expert workshops with mobility representatives of Vienna's planning department, normative assumptions were selected for each site based on the City's strategic development goals. They respond to the following policy questions:

- Restrictive vs. supportive provision of infrastructure for shared automated on-demand services (e.g., loading zones)?

- Restrictive vs. supportive parking management?

- Reallocation of on-street parking in favor of added travel lanes vs. lanes for active mobility modes and improved livability of public spaces?

- Static vs. dynamic prioritization of curb access according to land use and time of day?
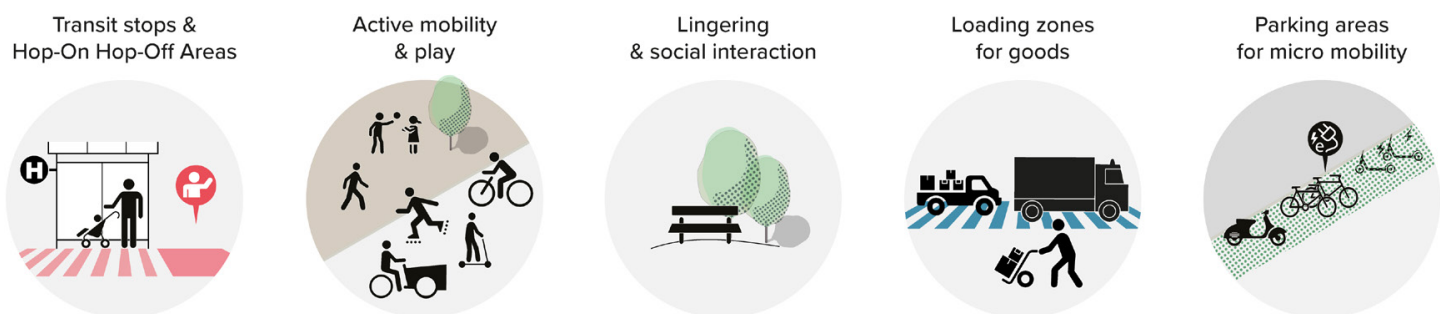

Figure 2. Shifting forms of use in public space (Bruck et al., 2021)

\section{$3 \quad$ Results}

To give an example of how to conduct the integrated assessment, this section presents the results for an inner-city commercial street affected by changing traffic patterns and spatial demands (Figure 3). 


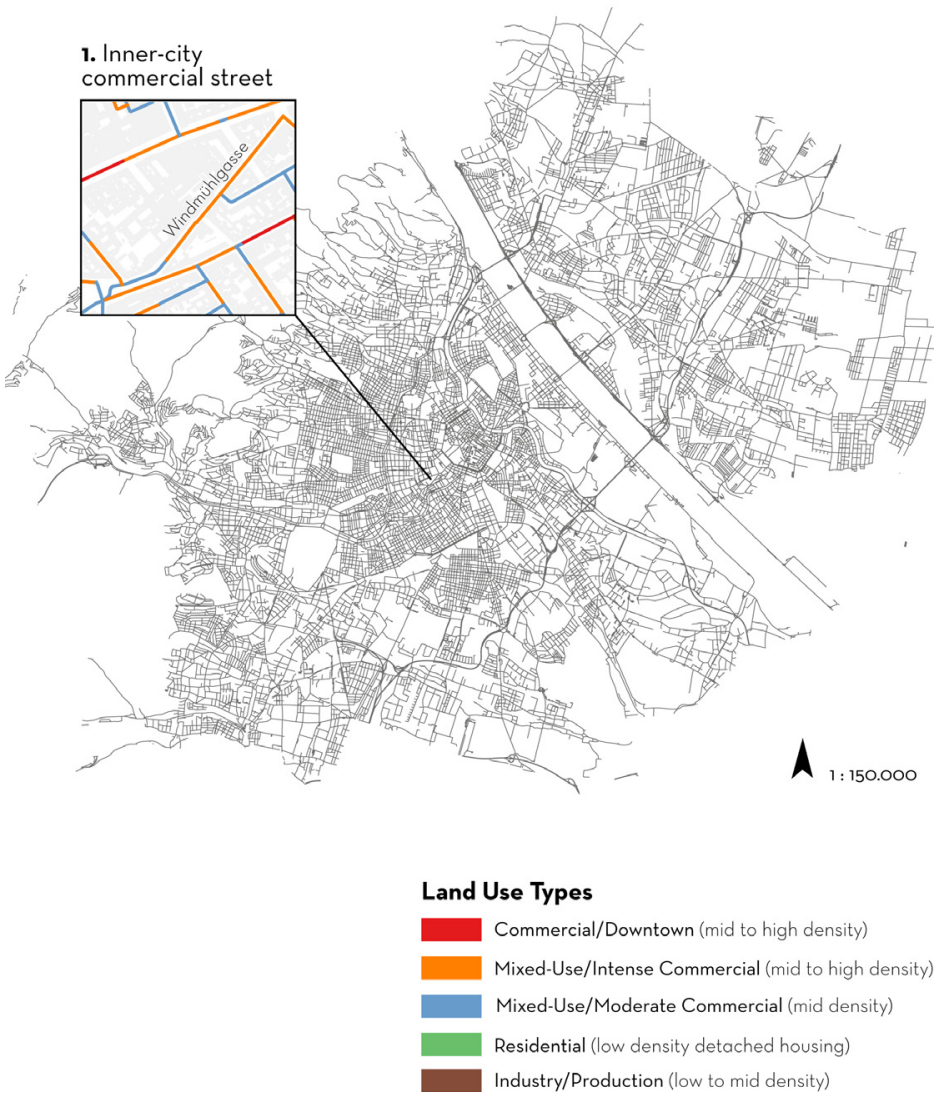

Figure 3. Location of inner-city commercial street

Before determining the visualized design options, the analytical steps described in the methods section are performed. For each site, the simulation results of individual scenarios are used to examine the compatibility between traffic changes due to $\mathrm{AVs}$ and existing land use, as well as the spatial implications for street designs. While the following description focusses on the implications for an inner-city commercial street, Section 4 will discuss the results in relation to other urban street typologies.

\subsection{Traffic-land use compatibility and street design impacts of AVs in an inner-city commercial street}

\section{a) Compatibility}

The approach of the traffic-land use compatibility assessment of street spaces with AVs builds on changes in traffic volume at peak hours. Figure 4 shows how the traffic volume, i.e., the number of vehicles at peak hour, changes within the selected inner-city street and surroundings by comparing the reference scenario to scenario 1 (automated shuttles providing a door-to-door service). Compared to the reference scenario, the number of vehicles increases in scenario 1 by up to 150 vehicles, within the selected street. An increase in the number of vehicles at peak hours is also shown for other parts of the lower level street network. In contrast, a lower number of vehicles is only shown on some segments of the main roads. 
Change of vehicles at peak hour

Comparison of scenario 1 and reference scenario

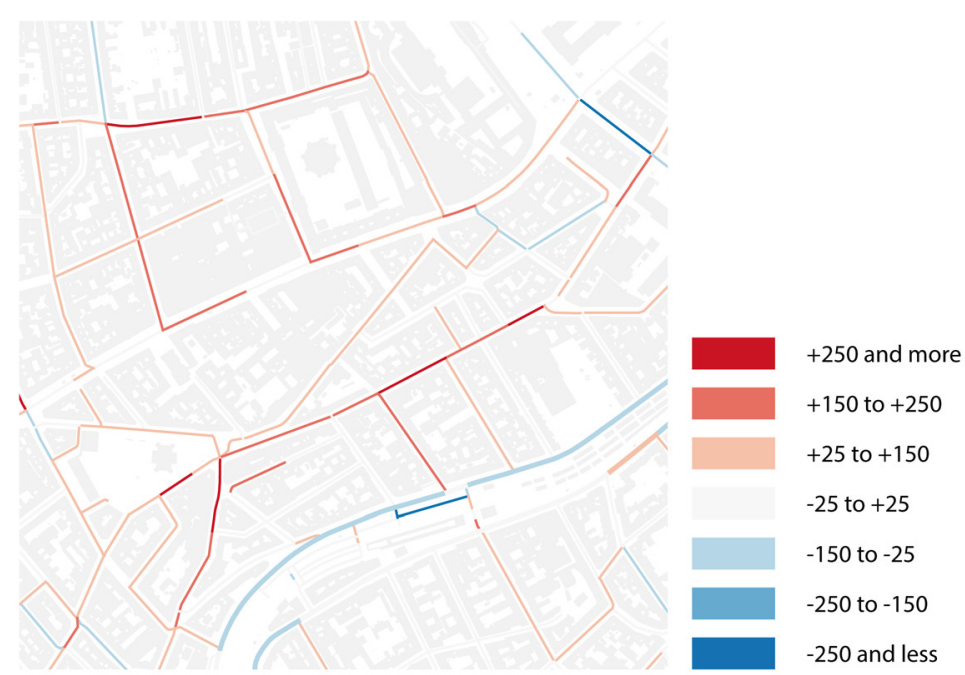

Figure 4. Change of vehicles at peak hour at street level for a selected inner-city street and surrounding streets: comparison between scenario 1 and reference scenario

Figure 5 shows the compatibility assessment of the inner-city street and surrounding streets for the reference scenario without $\mathrm{AVs}$ (left) and the change in compatibility by comparing the results for scenario 1 with the reference scenario (right). The results for the reference scenario show that current traffic volume is compatible in most segments of the lower level street network, as well as on the selected inner-city street. On some segments of the higher order streets, however, the current traffic volume is not compatible with the demands of surrounding land use and other modes.

In line with the aforementioned changes in traffic volume, the comparison between scenario 1 and reference scenario shows that the compatibility deteriorates on some street segments of the lower level street network. This also applies to one segment of the selected inner-city street. Looking at the entire area, hardly any compatibility improvement is shown. 
Reference scenario
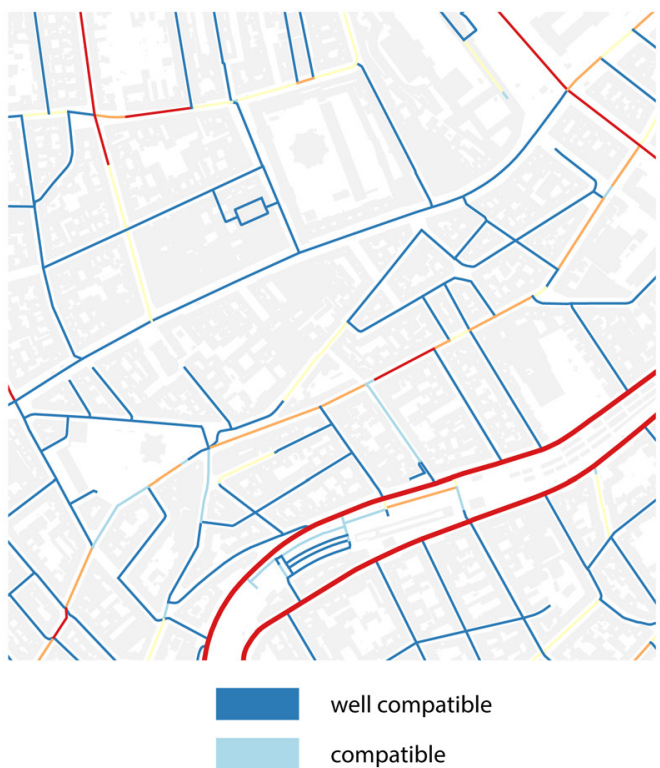

only just compatible

not compatible

completely not compatible
Comparison of scenario 1 and reference scenario

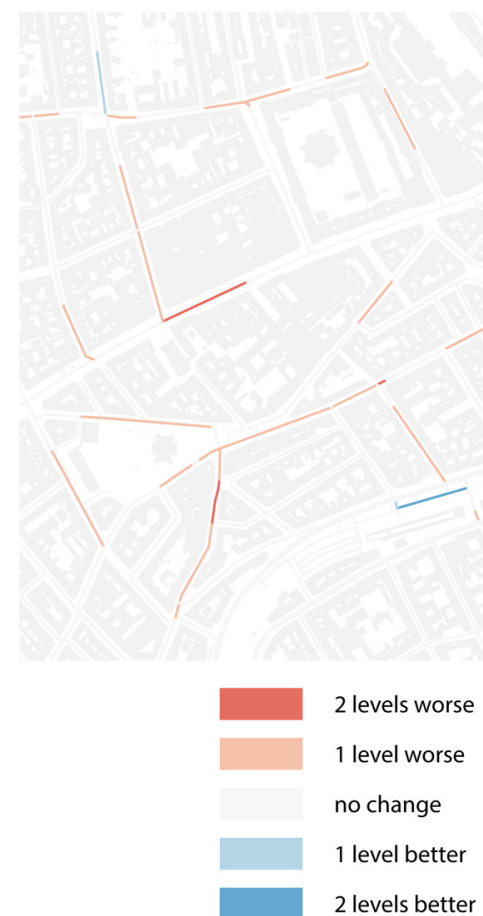

Figure 5. Overview of the compatibility assessment for the reference scenario and the comparison between scenario 1 and the reference scenario

\section{b) Distribution of passenger pickups and drop-offs}

For an urban environment that is characterized by high levels of retail, service, and office use, the results show that door-to-door service of shared automated shuttles would ensue a particularly large number of arrivals and departures during the afternoon hours. Figure 6 shows the approximated spatial distribution of the number of automated shuttles stopping to pick up or drop-off passengers at peak hours. Mapping the density distribution of access or egress moments along a street segment or part of the road network may reveal areas and times of significant demand. For planners, these may indicate areas that require particular attention concerning potential conflicts of use and the adequacy of provided infrastructure. 


\section{Scenario 1}

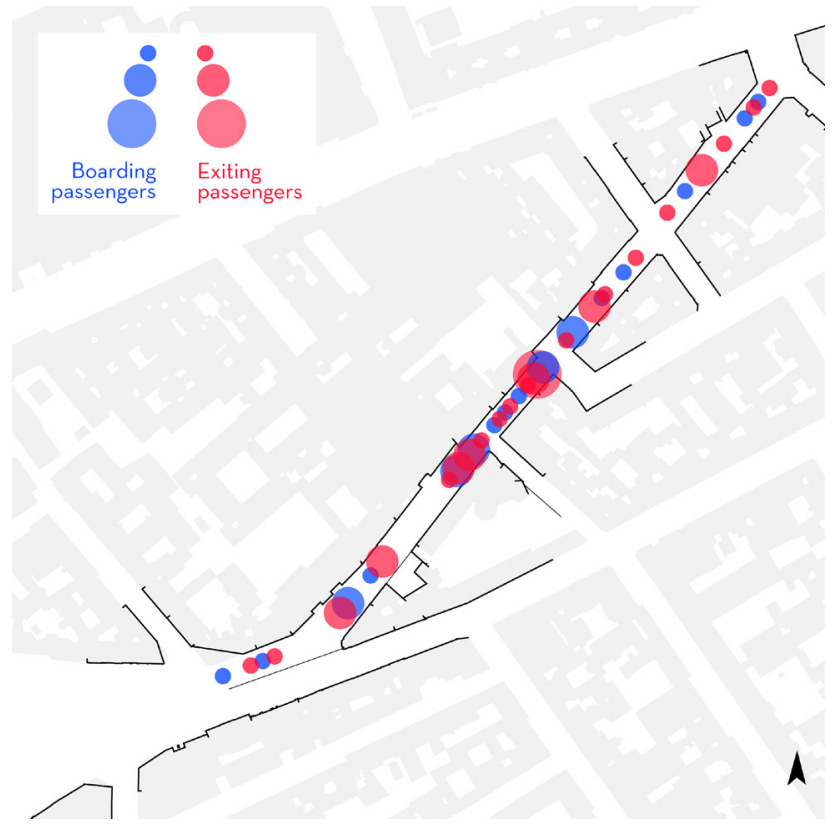

Distribution of pickup and drop-offs proportionally to existing sources and destinations

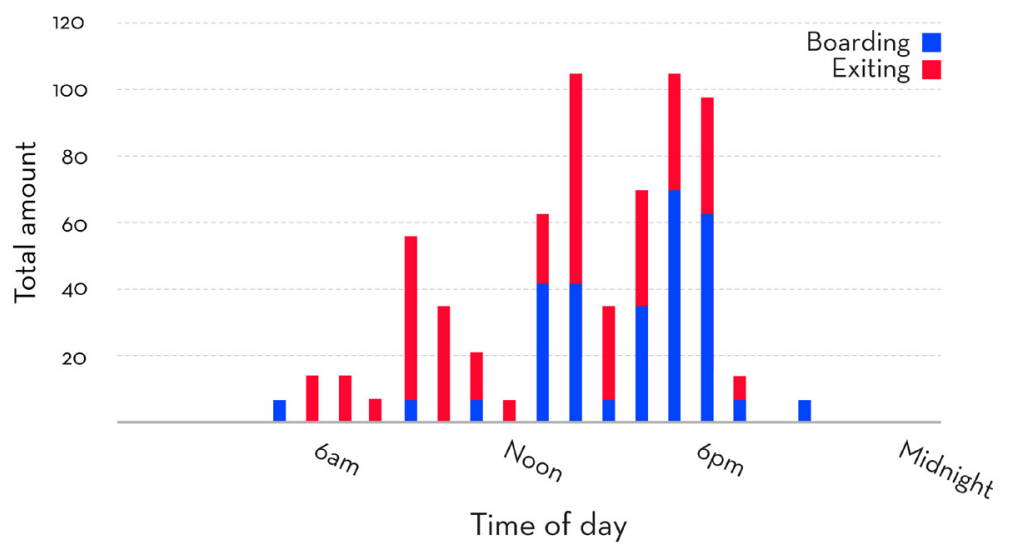

Daily dynamic

Figure 6. Approximated density of pickups and drop-offs at peak hour (above) and daily dynamic (below)

\section{c) Demand for pickup and drop-off zones}

A high concentration of stopping shuttles may also cause an increase in waiting passengers at the curb. Studies have shown (ITF, 2018; Stiglic et al., 2015) that the provision of dedicated pickup and dropoff zones may contribute to safer access and egress of passengers, but may also ease trip bundling and ride-pooling. Figure 7 shows the approximated demand for pickup and drop-off zones for an innercity commercial street based on its peak hour turnover. Two zones of equal dimension are located at a 100-to-200-meter distance serving the average demand, while a third zone is suggested as a temporary addition during rush hours in order to allow shuttles to evade occupied zones. 


\section{Scenario 1}

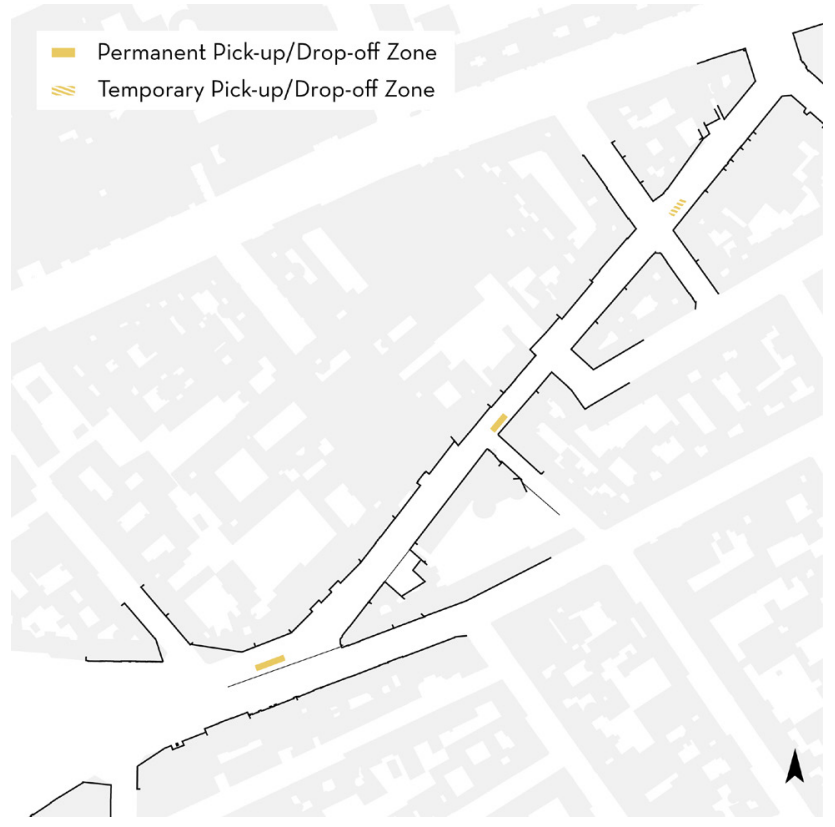

Distribution of pickup and drop-off bays every 100-200m

Figure 7. Approximating the demand for pickup and drop-off bays

\section{d) Parking demand for waiting vehicles}

Alongside the spatial demand for pickup and drop-off zones, empty AVs may cause parking demand, if increased vehicle travel due to deadheading between passenger trips is to be mitigated (Kondor et al., 2020). Figure 8 shows a rough approximation of shuttles' short-term parking demand for an inner-city commercial street based on vehicles' median waiting time. The diagram of the daily dynamic further shows that the peak parking demand coincides with the peak in passenger pickups and drop-offs. As it was shown by Kondor et al. (2020) the degree of short-term parking demand will ultimately depend on the operating radius of automated shuttles, as well as on public policy and operators' service models. 
Scenario 1

- Waiting autonomous shuttle

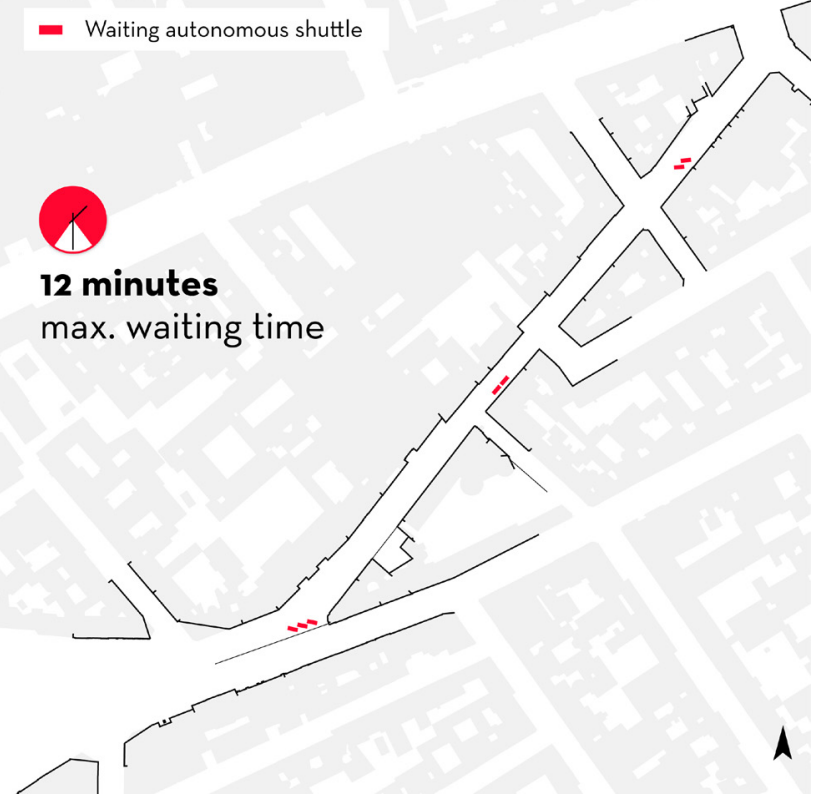

Approximated amount of simultaneously waiting vehicles

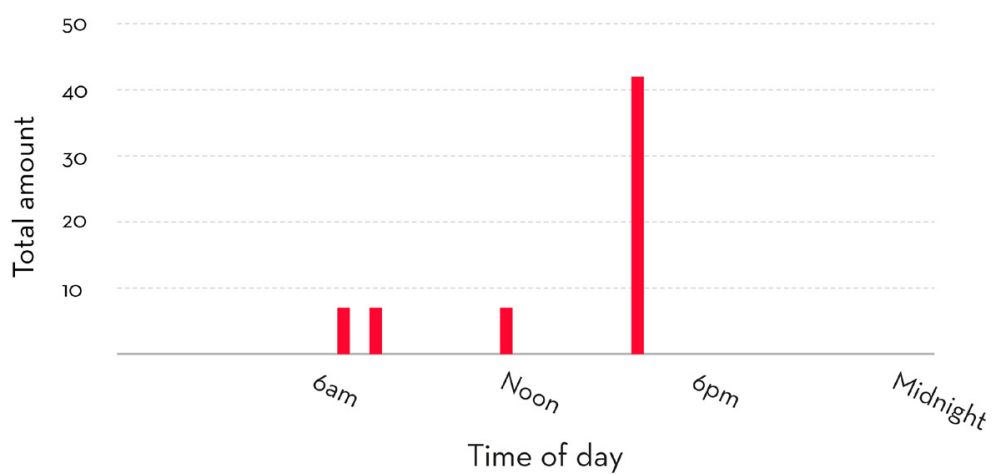

Daily dynamic

Figure 8. Approximated demand for short-term parking of waiting automated shuttles

\subsection{Street space transformation}

The integrated assessment clearly shows that in a future scenario where shared automated shuttles navigate urban streets, demand for curb access and street space will further diversify and increase (Marsden et al., 2020). The visualized transformations of street space illustrate means of integrating the functional requirements of shared automated shuttles, while also providing space for other uses which correspond with adjacent land use (Figure 9). 


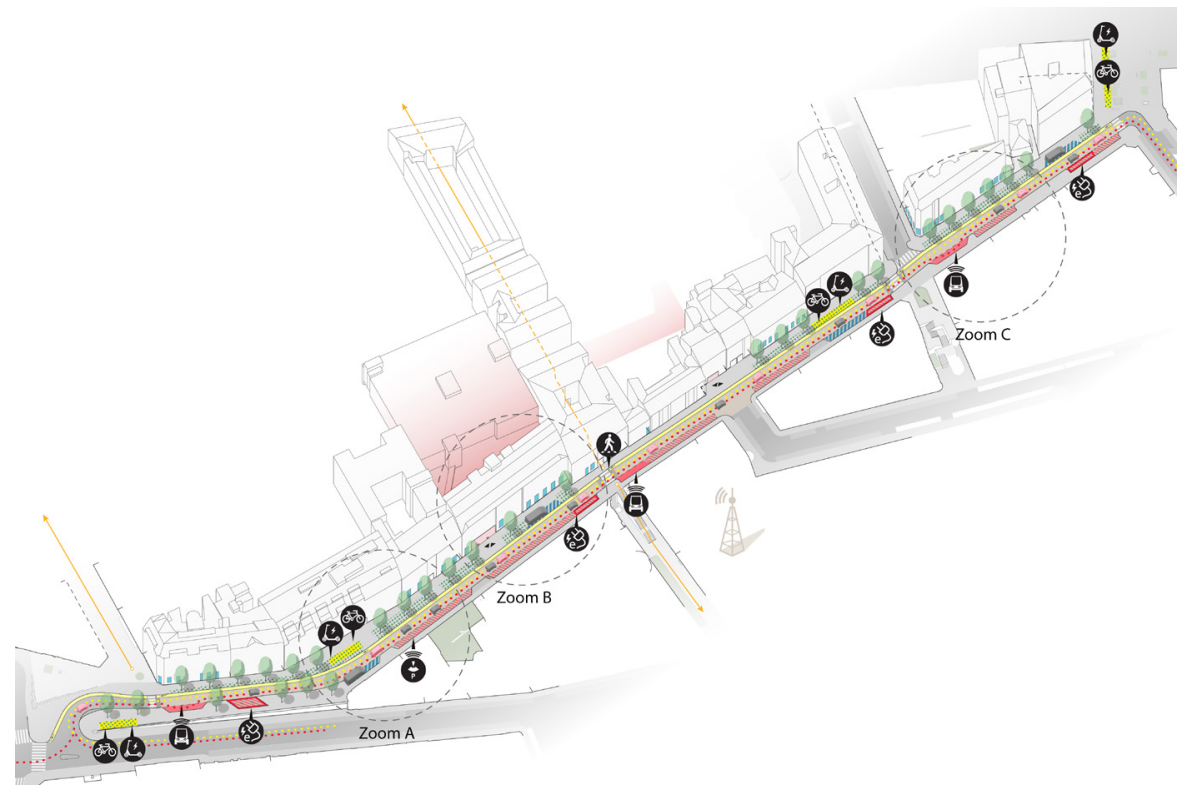

Figure 9. Design changes in an inner-city commercial street

To conceptualize the transformation of street space, simulation results are supplemented by literature-based assumptions and normative development objectives (Table 7).

Table 7. Influencing variables for the visualization of possible development directions

\begin{tabular}{|c|c|c|}
\hline Scenario assumptions & Literature-based assumptions & $\begin{array}{c}\text { Normative assumptions based on Vienna's } \\
\text { urban development goals }\end{array}$ \\
\hline $\begin{array}{l}\text { Introduction of automated on-demand } \\
\text { shuttles providing a door-to-door } \\
\text { service on low-ranking streets as an } \\
\text { alternative mobility option alongside } \\
\text { public transit and private motorized } \\
\text { vehicles, } \\
\text { Overnight, automated shuttles are } \\
\text { parked in public spaces near sources } \\
\text { and destinations, } \\
\text { Integration of e-charging stations in } \\
\text { proximity to places of high activity } \\
\text { density. }\end{array}$ & $\begin{array}{l}\text { Reduction of parking demand on } \\
\text { public streets by } 25 \% \text { to } 75 \% \text { due to } \\
\text { a shift towards shared autonomous } \\
\text { shuttles in combination with a public } \\
\text { transit network and provision of short- } \\
\text { term parking for waiting autonomous } \\
\text { shuttles in public spaces (Zhang \& } \\
\text { Wang, 2020), } \\
\text { Provision of passenger loading zones } \\
\text { and collection points to facilitate higher } \\
\text { occupancy rates (Stiglic et al., 2015). }\end{array}$ & $\begin{array}{l}\text { Redistribution of street space in favor } \\
\text { of active mobility and micromobil- } \\
\text { ity offers, including the redesign of } \\
\text { approx. half of on-street parking (MA } \\
\text { 18, 2015), } \\
\text { Expansion of the cycling network } \\
\text { and improved safety for cyclists by } \\
\text { incorporating a cycling lane against the } \\
\text { one-way system (MA 18, 2015), } \\
\text { Climate adaptation by increasing the } \\
\text { proportion of green space, shading and } \\
\text { unsealing (MA 22, 2015), } \\
\text { The number of on-street e-charging } \\
\text { stations is aligned with the city's } \\
\text { fast-charging network - no standard } \\
\text { on-street charging, } \\
\text { Unchanged parking management. }\end{array}$ \\
\hline
\end{tabular}

\subsection{Alternative spatial developments}

\section{a) Facilitating the crossability of street space}

Measures to improve pedestrian crossing concern above all the reduction of traffic speeds and narrower lane widths (Schönauer et al., 2012). Beyond that, different streetscape designs and features may be suitable for a neighborhood street with high levels of retail activity. If a large proportion of parking is kept, 
pedestrian crossing may be improved by installing curb extensions (Figure 10, left). These narrow a street space physically and improve pedestrian visibility while encouraging slower speeds and adding public space (NACTO, 2013: 45). Alternatively, a shared space scheme may be applied that gives equal priority to different modes and reduces spatial barriers between activity zones and travel lanes (Karndacharuk et al., 2014). Accessibility and a sense of place may be promoted, if a level surface with continuous paving is applied (Figure 10, right). Former on-street parking may be converted into additional space for recreation and more diverse street furniture, such as trees, seating, and lighting.
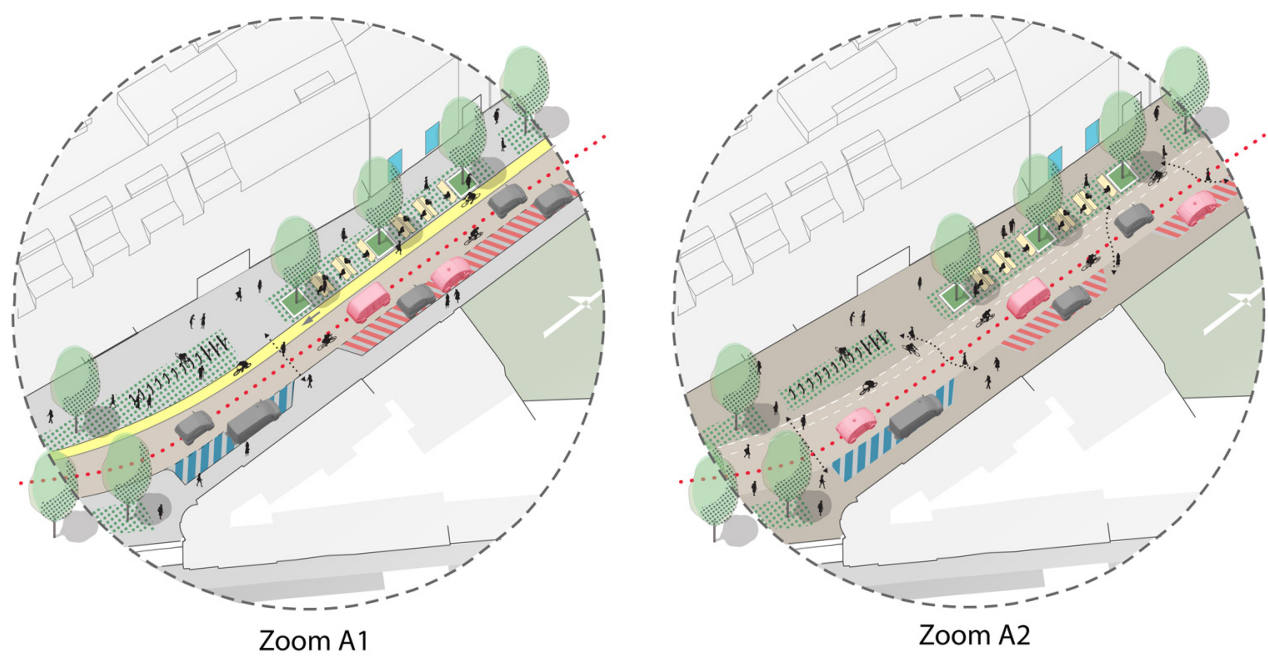

Figure 10. Alternative design options for crossability

\section{b) Providing space for short-term parking}

Providing short-term parking in proximity to departure locations and destinations could mitigate added traffic due to the deadheading of AVs. The amount of space required is not only related to fleet size, but also to the search radius within which automated shuttles would pick up passengers (Kondor et al., 2020). If short-term parking space is provided in street spaces, this could lead to considerable demand for space from stationary traffic, depending on the waiting time of vehicles (Figure 11, left). Alternatively, adjacent garages that are vacant or under-utilized could be turned into mobility hubs. Automated shuttles could be required to use these, not only for overnight parking, but also for short-term parking and charging during the day (Figure 11, right). In return, street space could be reallocated for added public space. 


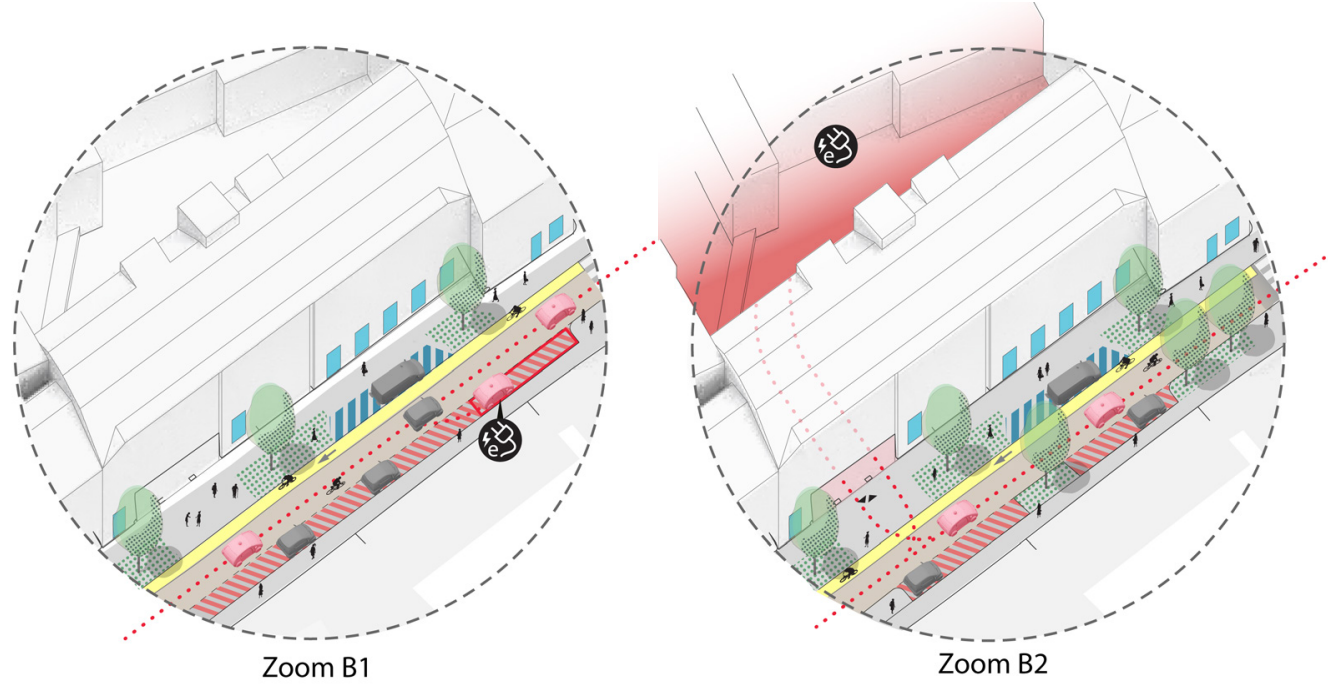

Figure 11. Alternative short-term parking solutions

\section{c) Pickup and drop-off zones}

There are different ways to respond to an increasing demand for zones in which passengers can board and exit automated shuttles. Whether pickup and drop-off zones are integrated on-street, meaning, shuttles stop in the lane closest to the parking lane, or whether they are provided in the form of bays with direct access to sidewalks, may impact traffic flow and user's travel time (ITF, 2018). If stopping bays are incorporated at the curb (Figure 12, left), negative impacts on traffic flow may be mitigated and safe interaction between pedestrians and cyclists enhanced (ibid). In contrast, if pickup and drop-off zones are provided on-street, stopping vehicles will to some extent induce queueing or, depending on street widths, overtaking manuevers (Figure 12, right). This may cause longer travel times, but could contribute to making motorized transport less attractive and incentivize active mobility.
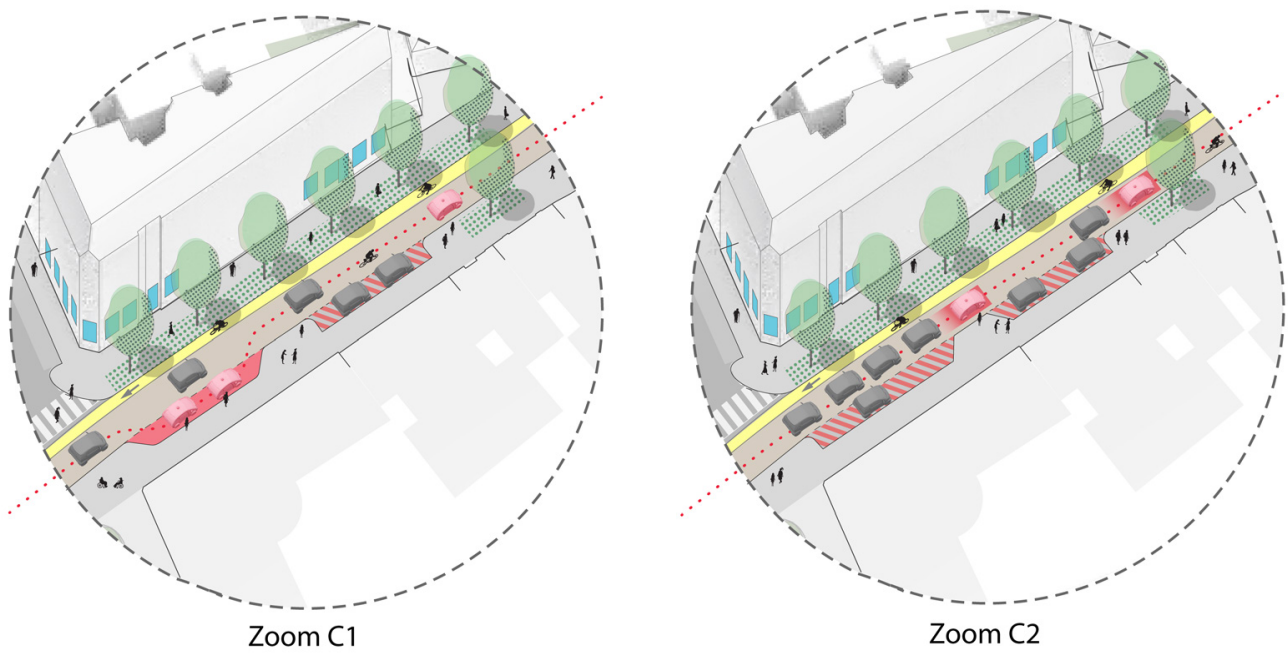

Figure 12. Alternative solutions for pickup and drop-off points 


\section{$4 \quad$ Discussion}

\subsection{Comparison of AVs' impacts on land use and street typologies across neighborhoods}

For the purpose of this paper, results were presented for only one street typology. The overall study, however, examined the impacts of $\mathrm{AVs}$ in different neighborhoods with varying land use and street typologies, i.e., an inner-city commercial street, a suburban arterial with a tramway, and an industrial access street. The analysis confirms earlier research in showing that spatial implications, such as changed traffic-land use compatibility, functional demands, and street space allocation significantly differ across urban areas:

- Inner-city street with intensive commercial use: For this area, the simulation results indicate that automated shuttles (scenario 1) providing door-to-door service would cause an increase in traffic, especially, if there are no supporting policies or regulatory measures. This negatively impacts the compatibility of traffic with existing land-use demands and related uses which strongly characterize such streets (e.g., pedestrian and bicycle traffic, gastronomic use, leisure, etc.). Today, the spatial integration of different demands for street space is already constrained by high building densities and narrow street widths with available street space largely distributed in favor of car parking. The introduction of automated on-demand ride services would, thus, increase pressure on spatial distribution and require proactive planning and targeted measures, by 1 ) reducing the spatial demand of motorized vehicles such as less parking and narrower roadways to promote interaction safety between different mobility modes and to dedicate sufficient space to green areas, lingering, and commercial uses; 2 ) provide dedicated pickup and drop-off zones; 3) reduce traffic speeds; and 4) extend pedestrian and cycling infrastructure.

- Suburban arterial with tramway: For this type of suburban street, which is often characterized by high traffic volumes, results show that a stop-based automated shuttle service (scenario 2) may reduce congestion levels and positively affect the compatibility of traffic volumes with surrounding land use. This may represent an opportunity for urban development, if planning measures are implemented that counteract the neighborhood-separating effect of main roads and contribute to street livability, by 1) enhancing mobility hubs, such as tramway stations through furniture and design accents; 2) improving pedestrian accessibility and attractiveness of spatial connections into surrounding neighborhoods; 3) converting parking in favor of wider sidewalks and green infrastructure to improve the attractiveness of the public realm and the frequency of adjacent store fronts, restaurants, or services; and 4) integrating stopping areas for automated shuttles at existing transit stops in such a way that walking distances are kept short and seamless transfers are possible.

- Industrial access street: In these kinds of largely uninhabited industrial locations, the use of automated shuttles providing door-to-door (scenario 1) or stop-based services (scenario 2) does not lead to any noticeable change in traffic-land use compatibility. Instead, positive spatial effects may occur when automated shuttles provide shared door-to-door travel within a confined operational range, e.g., a business park. Automated shuttle services may then be used to provide an alternative form of organizing internal mobility and access from subway stations, train stations, or park-and-ride facilities. In effect, a significant share of commuter traffic could be shifted to transit and the spatial demand of motorized vehicles reduced. Actualizing spatial development potentials in industrial areas and business parks would require targeted planning approaches, which 1) increase the attractiveness of shared and active mobility on the last mile by redistributing street space in favor of pickup and drop-off facilities, continuous bicycle and green infrastructure; 2) encourage the transformation of existing train stations and park and ride facilities into mobility hubs that may accommodate future shuttle fleets; and 3) promote densification and greater diversity of land use when developing freed-up land on company 
premises. However, the potential increase of deadheading caused by a door-to-door service must be taken seriously and mitigated by respective transport policies, e.g., pricing models, enforcing higher vehicle occupancy.

\subsection{Regulatory considerations concerning operational conditions}

The contextual differentiation of traffic changes and visualization of potential implications for street designs provide indicators for legislators and planners regarding: what the trade-offs of a system change may be and which regulatory levers may be proactively applied during the transition to automated mobility. The environmental contexts of use require more deliberate assessments to adequately determine the circumstances under which AVs may contribute to a safe, equitable, and effective transport system (Stayton \& Stilgoe, 2020). The compatibility study makes it clear that proactive policy measures will be necessary to reduce vehicular dominance in street spaces, to manage diversifying demands, and to sustain street livability (Appleyard \& Riggs, 2018; Karndacharuk et al., 2014; Marsden et al., 2020). In advance of a widespread adoption of AVs, several planning and regulatory steps require consideration:

- To reap the spatial benefits of automated vehicles (e.g., the conversion of street space in favor of diverse modes, a sense of place, and street livability), regulatory decisions are required that incentivize higher vehicle occupancy rates, shared journeys, and carpooling. After all, studies show (e.g., Zhang \& Wang, 2020) that ride-sharing has a much higher impact on parking demand reductions than vehicle automation. Designating pickup and drop-off zones for shared (on-demand) services could be one measure alongside others, as it facilitates trip bundling and reduces detours. In addition, the provision of designated loading zones may enhance the spatial organization of mobility services and thus contribute to the clarity of public space, road safety, and efficient traffic flow.

- A city-wide classification of the road network according to automated use cases, traffic speeds, and land use. Various studies have touched upon the issue of differentiating operational conditions for AVs across urban areas (e.g., González-González et al., 2020), but so far, they lack systematic differentiation of land-use types and street typologies. Street networks will need to be categorized in a more encompassing manner by reviewing beneficial implications (e.g., improved accessibility), as much as potential risks (e.g., increased traffic volumes and curbside demand, or lower levels of transit and active mobility) in relation to adjacent land use. AVs will not only impact the performance of street spaces, e.g., road-user interaction, freedom of movement, formal and informal activities, but also the relation to the surrounding built environment, its accessibility, and livability.

- Prioritizing active mobility and micromobility in traffic and street designs by converting travel lanes to slower modes. AVs have the potential to be programmed and respond to digital fencing, which reduces the need for physical signage and barriers. Depending on street typology, active mobility can be enhanced by lowering speed-limits, implementing shared space schemes, and a clear organization of parking and loading zones. On higher order streets, such as arterials, under-utilized travel lanes may be converted to designated bike lanes or central medians. In effect, traffic safety may be enhanced and the separating effects of automated traffic mitigated.

- In light of a potentially significant parking demand caused by empty automated shuttles, proactive planning in the form of parking studies, inventories, and strategic parking infrastructure plans is required (Zhang \& Wang, 2020). In this fashion, shared fleet parking and maintenance should be factored in when planning future parking facilities, bus depots, or transit hubs.

- The environmental impacts of deadheading and increased vehicle miles travelled by ride-hailing companies receive increasing attention (Anair et al., 2020). When considering corresponding policy, policymakers are required to anticipate the long-term adoption of automated fleets, 
which may further induce traffic demand and empty vehicle miles travelled, due to user convenience and operational cost benefits.

\subsection{Limitations and further research}

The methodology developed for this study represents a two-step approach to delineate street design impacts when using a transport simulation model. Some analytical challenges were met, above all since the baseline simulation was conducted on the city scale of Vienna. For the purpose of analyzing traffic and urban impacts on a street-scale, more fine-grained input data, micro-simulations, and an encompassing parking inventory would undoubtedly lead to more precise assessments.

With regards to the defined variables of functional demand, it is important to note that the approximation was limited in two specific regards. First, concerning the accuracy of the output data, which was provided on a street-level basis, rather than based on exact coordinates. Secondly, concerning the sample simulation, which was based on $15 \%$ of the total traffic demand. In effect, the absolute values of spatial demand (number of passenger loading/unloading events and number of waiting vehicles at peak hour) need to be treated with care. The results are inevitably distorted by the inaccuracy of input data at the micro level, the extrapolation factor, and the assumptions on transport supply with AVs that underlie the scenarios (Curtis et al., 2020). This is to show that further research integrating micro simulations is required to assess $\mathrm{AV}$-related street dynamics and land-use impacts more accurately. Furthermore, local parking demand models are necessary, which factor in different adoption levels of shared mobility services with and without automation.

Moreover, the baseline simulation, which was used as input for the integrated assessment, showed limitations in that it did not account for induced demand likely ensuing from AVs, e.g., due to enhanced accessibility for the mobility-impaired, elderly, or very young. It may be assumed that the presented compatibility and street design impacts would be stronger if induced demand was considered. In addition, future modelling would benefit from incorporating transport policy measures, such as incentive systems for higher occupancy rates, access restrictions depending on the street category, and pricing policies. After all, policies and regulatory measures will have a significant impact on how AVs may ultimately affect changes in traffic demand, designs of streetscapes, and urban form.

\section{Conclusion}

The study presented in this paper applied an integrated assessment of AVs' traffic and urban effects at the neighborhood level for the city of Vienna, Austria. Its aim was three-fold: 1) show to what extent changing traffic volumes are compatible with the urban form and land use of different neighborhoods; 2) approximate AVs' effects on urban space, which may strain some street typologies more than others; and 3) visualize possible design strategies, which add to the livability of streets and integrate measures to optimize shared automated mobility systems such as designated pickup and drop-off points.

Rather than showing idealized future visions, the study's visualized spatial transformations reveal fields of tension concerning spatial developments, which are derived from the integrated assessment of AVs' traffic and urban effects. Future street spaces may change in vastly different ways, depending on whether or not municipalities respond through informed regulatory measures. As such, the visualizations add another dimension to scenario studies, providing a useful tool to support long-term thinking and proactive decision-making concerning transport and urban development policy (Stead \& Vaddadi, 2019: 126).

In addition, the integrated approach of combining traffic compatibility analyses with spatial im- 
plications of AVs, highlights that opportunities for spatial conversion and risks of environmental harm will vary across neighborhoods and street typologies. In light of a pressing need to manage increasingly diverse demands on street spaces, the results of the study may inform the adaptation of traffic and urban design policies, e.g., parking policy, curbside management strategies, pricing models, or cycling infrastructure. Put more concretely, analyzing the intensity and daily/weekly dynamic of passenger loading and unloading events along a particular street may, for instance, help to evaluate the adequacy of street designs and provision of infrastructure, while also highlighting areas of conflicting use.

Further studies are necessary that consider contextual circumstances, particularly given that integrated and spatially differentiated traffic and urban design impacts of AVs have been under-examined. Future research is also needed in terms of more refined modelling studies, better alignment of interdisciplinary examinations, and local pilot initiatives. All of these may provide critical input for more contextually oriented decision-making. A refined understanding of how different kinds of AVs affect certain neighborhoods and street typologies, depending on existing land-use demands, is crucial in determining locally adequate operational conditions for AVs.

\section{Acknowledgments}

The presented results were developed as part of the research study "Street Design Impacts and Traffic-Land Use Compatibility of Automated Driving in Vienna," a research cooperation between the future.lab Research Centre, TU Wien, and the MA 18-Department for Urban Development and Planning, Vienna City Administration. The research cooperation was established within the framework of the research project "auto.WAVES: Automated Driving-Impact Analysis Transport, Energy and City for the Vienna Region," funded by the FTI Innovation Fund of Wiener Stadtwerke from 2018 to 2020. 


\section{References}

Anair, D., Martin, J., Pinto de Moura, M., \& Goldman, J. (2020). Ride-hailing's climate risks: Steering growing industry toward a clean transportation future. Cambridge, MA: Union of Concerned Scientists. https://www.ucsusa.org/resources/ride-hailing-climate-risks

Appleyard, B., \& Riggs, W. (2018). A vision for livability. In W. Riggs (Ed.), Disruptive transport. Driverless cars, transport innovation and the sustainable city of tomorrow (pp. 189-203). Oxfordshire, UK: Routledge.

Auld, J., Verbas, O., Javanmardi, M., \& Rousseau, A. (2018). Impact of privately-owned level 4 CAV technologies on travel demand and energy. Procedia Computer Science, 130, 914-919. https://doi. org/10.1016/j.procs.2018.04.089

Baier, R., Hebel, C., Jachtmann, Y., Reinartz, A., Schäfer, K. H., \& Warnecke, A. (2011). Stadt Mönchengladbach. Untersuchungen zur Verkehrsentwicklungsplan. Aachen, Germany: BSV-Büro für Stadt- und Verkehrsplanung. https:/www.yumpu.com/de/document/view/5809760/stadtmonchengladbach-untersuchungen-zum-

Boesch, P. M., Ciari, F., \& Axhausen, K. W. (2016). Automated vehicle fleet sizes required to serve different levels of demand. Transportation Research Record, 2542(1), 111-119. https://doi. org/10.3141/2542-13

Boesch, P. M., Ciari, F., \& Axhausen, K.W. (2018). Transport policy optimization with autonomous vehicles. Transportation Research Record, 2672, 698-707. https://doi.org/10.1177/0361198118791391

Bruck, E. M., Scheuvens, R., \& Berger, M. (2021). Steuerung und Gestaltung von räumlichen Schnittstellen der Mobilität. In M. Mitteregger, E. M. Bruck, A. Soteropoulos, A. Stickler, M. Berger, J.S. Dangschat, R. Scheuvens, \& I. Banerjee (Eds.), AVENUE21: Politische und planerische Aspekte der automatisierten Mobilität (pp. 133-158). Berlin: Springer. https://link.springer.com/ book/10.1007/978-3-662-63354-0

Bühlmann, F. \& Laube, M. (2013). Verträglichkeit Straßenraum. Methodik und Ergebnisse. Zurich: Kanton Zurich. https://docplayer.org/72188141-Vertraeglichkeit-strassenraum-methodik-undergebnisse-januar-2013.html

Childress, S., Nichols, B., Charlton, B., \& Coe, S. (2015). Using an activity-based model to explore the potential impacts of automated vehicles. Transportation Research Record, 2493, 99-106. https:// doi.org/10.3141\%2F2493-11

Curtis, C., McLeod, S., Hultén, J., Pettersson-Lofstedt, F., Paulsson, A., \& Hedegaard Sørensen, C. (2020). Knowledge for policy-making in times of uncertainty: The case of autonomous vehicle model results. Transport Reviews, 41(4), 478-498.

Fehr \& Peers. (2018). San Francisco curb study. San Francisco: Uber Technologies. https://www.fehrandpeers.com/curbs-of-the-future/

Fehr \& Peers. (2019). Cincinnati curb study. Cincinatti: City of Cincinnati and Uber Technologies. https://www.fehrandpeers.com/curbs-of-the-future/

Frehn, M., Steinberg, G., \& Schröder, S. (2013). Methodik und Ergebnisse der Straßenraumverträglichkeit. Verkehrsentwicklungsplan Bremen 2025. Retrieved from http://www.bau.bremen.de/sixcms/media.php/13/130228_E03_Strassenraumvertraeglichkeit_Methodik_Ergebnisse.pdf

Friedrich, B. (2016). The effect of automated vehicles on traffic. In M. Maurer, C. J. Gerdes, B. Lenz, $\&$ H. Winner (Eds.), Automated driving (pp. 317-334). Berlin: Springer.

Fulton, L. M., Mason, J., \& Meroux, D. (2017). Three revolutions in urban transportation: How to achieve the full potential of vehicle electrification, automation, and shared mobility in urban transportation systems around the world by 2050. Davis, CA: University of California Davis Institute of Transportation Studies report to the Institute for Transportation and Development Policy. https://itdpdotorg. 
wpengine.com/wp-content/uploads/2017/04/ITDP-3R-Report-FINAL.pdf

Gehl Architects. (2009). Downtown Seattle: Public spaces \& public life. Seattle: City of Seattle. www. seattle.gov/Documents/Departments/SDCI/Codes/PublicSpacesLifeIntro.pdf

Gelauff, G., Ossokina, I., \& Teulings, C. (2017). Spatial effects of automated driving: dispersion, concentration, or both. The Hague: KIM-Netherlands Institute for Transport Policy Analysis.

González-González, E., Nogués, S., \& Stead, D. (2020). Parking futures: Preparing European cities for the advent of automated vehicles. Land Use Policy, 91, 104010. https://doi.org/10.1016/j.landusepol.2019.05.029

Harb, M., Stathopoulos, A., Shiftan, Y., \& Walker, J. L. (2021). What do we (not) know about our future with automated vehicles? Transport Research Part C, 123, 102948. https://doi.org/10.1016/j. trc.2020.102948

Horni, A., Nagel, K., \& Axhausen, K. W. (2016). The multi-agent transport simulation MATSim. London: Ubiquity.

ITF. (2018). The shared-use city: Managing the curb. Corporate partnership board report. Paris: International Transport Forum, OECD. https://www.itf-oecd.org/sites/default/files/docs/shared-use-citymanaging-curb_3.pdf

Karndacharuk, A., Wilson, D. J., \& Dunn, R. (2014). A review of the evolution of shared (street) space concepts in urban environments. Transport Reviews, 34(2), 190-220. https://doi.org/10.1080/014 41647.2014.893038

Kondor, D., Santi, P., Le, D.-T., Zhang, X., Millard-Ball, A., \& Ratti, C. (2020). Addressing the minimum parking' problem for on-demand mobility. ArXiv:1808.05935. Retrieved from http://arxiv.org/ abs/1808.05935

Liu, J., Kockelman, K. M., Boesch, P. M., \& Ciari, F. (2017). Tracking a system of shared automated vehicles across the Austin, Texas, network using agent-based simulation. Transportation, 44(6), 1261-1278. https://doi.org/10.1007/s11116-017-9811-1

MA 18 - Stadtentwicklung und Stadtplanung. (2015). STEP 2025. Fachkonzept Mobilität, Wien. Retrieved from https://www.wien.gv.at/stadtentwicklung/studien/pdf/b008390b.pdf

MA 22 - Wiener umweltschutzabteilung. (2015). Urban heat islands: Strategieplan Wien. Retrived from https://www.wien.gv.at/umweltschutz/raum/pdf/uhi-strategieplan.pdf

Marsden, G., Docherty, I., \& Dowling, R. (2020). Parking futures: Curbside management in the era of 'new mobility' services in British and Australian cities. Land Use Policy, 91, 104012. https://doi. org/10.1016/j.landusepol.2019.05.031

Meyer, J., Becker, H., Bösch, P. M., \& Axhausen, K. W. (2017). Autonomous vehicles: The next jump in accessibilities? Research in Transportation Economics, 62, 80-91. https://doi.org/10.1016/j.retrec.2017.03.005

Milakis, D., van Arem, B. \& van Wee, B. (2017). Policy and society related implications of automated driving: A review of literature and directions for future research. Journal of Intelligent Transportation Systems, 21(4), 324-348. https://doi.org/10.1080/15472450.2017.1291351

NACTO. (2013). Urban street design guide. Washington, DC: Island Press

Oblozinska, Z., \& Axhausen, K. W. (2004). Dokumentation der Messung von Verkehrserzeugungsraten (Arbeitsbericht Verkehrs- und Raumplanung 265). (IVT). Zürich: Institut für Verkehrsplanung und Transportsysteme.

Schönauer, R., Stubenschrott, M., Schrom-Feiertag, H., \& Menšik, K. (2012). Social and spatial behavior in shared spaces. In M. Schrenk, V. V. Popovich, P. Zeile, \& P. Elisei (Eds.), REAL CORP 2012 Proceedings (pp. 759-767). Retrieved from https://www.corp.at/archive/CORP2012_64.pdf

Schwartz, S. (2017). New mobility playbook 1, Appendix B. (Technical report). Seattle: Seattle Depart- 
ment of Transportation, King County Metro. https:/www.seattle.gov/Documents/Departments/ SDOT/NewMobilityProgram/AppendixB.pdf

Soteropoulos, A., Berger, M., \& Ciari, F. (2019). Impacts of automated vehicles on travel behaviour and land use: An international review of modelling studies. Transport Reviews, 39(1), 29-49.

Soteropoulos, A., Berger, M., \& Mitteregger, M. (2021). Compatibility of automated vehicles in street spaces: Considerations for a sustainable implementation. Sustainability, 13(5), 2732. https://doi.org /10.1080/01441647.2018.1523253

Spieser, K., Treleaven, K., Zhang, R., Frazzoli, E., Morton, D., \& Pavone, M. (2014). Toward a systemic approach to the design and evaluation of automated mobility-on-demand systems: A case study in Singapore. In G. Meyer, \& S. Beiker (Eds.), Road vehicle automation. Lecture notes in mobility (pp. 229-245). Berlin: Springer. https://link.springer.com/chapter/10.1007/978-3-319-05990-7_20

Stayton, E., \& Stilgoe, J. (2020). It's time to rethink levels of automation for self-driving vehicles. SSRN Electronic Journal. Retrieved from http://dx.doi.org/10.2139/ssrn.3579386

Stead, D., \& Vaddadi, B. (2019). Automated vehicles and how they may affect urban form: A review of recent scenario studies. Cities, 92, 125-133. https://doi.org/10.1016/j.cities.2019.03.020

Stiglic, M., Agatz, N., Savelsbergh, M., \& Gradisar, M. (2015). The benefits of meeting points in ridesharing systems. Transportation Research Part B: Methodological, 82, 36-53. https://doi.org/10.1016/j. trb.2015.07.025

Thakur, P., Kinghorn, R., \& Grace, R. (2016). Urban form and function in the autonomous era. Australasian Transport Research Forum Proceedings, November 2016. Retrieved from http://atrf.info/papers/2016/files/ATRF2016_paper_138.pdf

von Mörner, J., Müller, B., \& Topp, H. (1984). Design and design of inner-city streets. Research on road construction and road traffic technology (Report 425). Bonn, Germany: Federal Ministry for Transport.

Wellik, T., \& Kockelman, K. (2020). Anticipating land-use impacts of self-driving vehicles in the Austin, Texas, region. Journal of Transport and Land Use, 13(1), 185-205. https://doi.org/10.5198/ jtlu.2020.1717

Zhang, W., Guhathakurta, S., Fang, J., \& Zhang, G. (2015). Exploring the impact of shared automated vehicles on urban parking demand: An agent-based simulation approach. Sustainable Cities and Society, 19, 34-45. https://doi.org/10.1016/j.scs.2015.07.006

Zhang, W., Guhathakurta, S., \& Khalil, E. B. (2018). The impact of private automated vehicles on vehicle ownership and unoccupied VMT generation. Transportation Research Part C: Emerging Technologies, 90, 156-165. https://doi.org/10.1016/j.trc.2018.03.005

Zhang, W., \& Wang, K. (2020). Parking futures: Shared automated vehicles and parking demand reduction trajectories in Atlanta. Land Use Policy, 91, 103963. https://doi.org/10.1016/j.landusepol.2019.04.024 